\title{
THERMAL UNITS REQUIREMENTS FOR DEVELOPMENT OF THE AMERICAN BOLLWORM, Helicoverpa armigera (HUBNER.) Adly, A.M. ${ }^{1}$; Amira Sh.M. Ibrahim ${ }^{2}$ and A.F. Ahmed ${ }^{1}$ 1-Plant Protection Research Institute, Agricultural Research Center ,Giza. 2-Faculty of Agriculture, Kafrelsheikh University, Kafr El-Sheikh, Egypt.
}

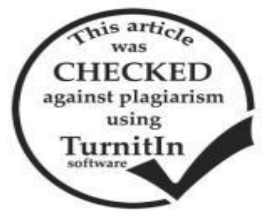

\section{ABSTRACT}

The present study was carried out under four constant temperatures of $20,23,26$ and $29^{\circ} \mathrm{C}$ each \pm 1 when the American bollworm, Helicoverpa armigera (Hubner) larvae were fed on the Lettuce vegetable leaves, Lactuca sativa $\mathrm{L}$. The time required for embryogenesis, larval duration and pupal duration as well as pre- and post-oviposition periods decreased as the temperatures increased from 20 to $29^{\circ} \mathrm{C}$. The lower threshold of development $\left(\mathrm{t}_{\mathrm{o}}\right)$ were $12.56,11.09,11.23$ and $9.99^{\circ} \mathrm{C}$ for incubation period, larvae, pupae and pre- oviposition period, respectively. The average accumulated thermal units required for development of the different stages was 43.05, 255.66, 231.29 and 9.99 degree-days for incubation period, larvae, pupae and pre-oviposition period; respectively. The lower threshold of development $\left(\mathrm{t}_{\mathrm{o}}\right)$ to complete a generation was $10.92^{\circ} \mathrm{C}$. The average accumulated thermal units required for a generation was 589.62 degree-days. The thermal units required to complete the development of different stages and completion one generation, as well as helping in the design of development indexes, determining the time required for these stages under fluctuating temperatures in field and forecasting system for establishing and develop the non chemical methods for controlling using the Helicoverpa armigera IPM program.

\section{INTRODUCTION}

Cotton is one of the field cash crops in Egypt. Insect pests are the most serious and important limiting factors of cotton production. The American bollworm, Helicoverpa armigera (Hubner) is one of the most important pests attaching cotton in Egypt, which causing great reduction in quantity and quality of the yield. This pest is most widely distributed throughout Africa, central and southern Asia to Japan and Philippines, the Middle East, Southern Europe, Eastern and Northern Australia, New Zealand and many eastern pacific Islands (Matthews and Turnstile, 2001). Although the use of insecticides is still the most effective method to control pests, it is becoming increasingly important to design and develop an alternative program safe to human and/or environment.The influence of temperature in determining the emergence development of insect population is well established by Ives (1973). Since the temperature is considered as an important environmental factor that affects the rate of development of the insects, and controlled the success of the insect to live in a given temperature, it was particularly as practical point of view interesting for economic insects to be obtained a useful and good forecast and prediction system of insect population (Wagner et al., 1984). This study was pointed mainly to the following aspects: relationship between temperature and rate of development, studying the biological aspects of $H$. armigera as a prior to limit its required thermal units to be used through forecasting system to establish an IPM program for $H$. armigera and the thermal units required to complete the development of different stages to complete one generation, as well as helping in the design of development indexes used for determining the times required for these stages under fluctuating temperatures in the field.

\section{MATERIALS AND METHODS}

\section{Insect rearing:}

Full grown larvae of the American bollworm, Helicoverpa armigera (Hubner) used in the current study was collected strawberry fields in Sharkia
Governorate during the late season of 2014 and transferred to the laboratory of the Bollworm Research Department, Plant Protection Research Institute. The larvae were reared on lettuce leaves, Lactuca sativa $\mathrm{L}$ under laboratory condition at $27 \pm{ }^{\circ} \mathrm{C}$ and $70 \pm 5 \%$ R.H.for three generations at least to become homogenous strain.

\section{Development of different stages}

All the $H$. armigera stages were kept under four constant temperatures at 20, 23, 26 and $29{ }^{\circ} \mathrm{C}$ to determine the rate of development. Eggs laid in the same day were placed in glass vials; four replicates of 100 eggs/each were used for each of the situations to be tested. Observations were made daily to record the time of hatchability. The incubation period and the embryo development rates were estimated. To study the larval development, 100 newly hatched larvae were transferred individually to glass tubes $(3 \times 10 \mathrm{~cm}) 25$ larvae/replicate containing fresh lettuce leaves which replaced with fresh another every one day. Each tube was plugged tightly with absorbent cotton and placed in an incubator for each temperature. The larvae were examined daily until pupation to estimate the larval duration. Newly formed pupae were collected on the same day of pupation and placed separately in a glass tube. Four replicates (each of 25 pupae) were placed at each tested temperature and observed daily till the adult emergence to estimate the duration of the pupae. After being sexed, the newly emerged moths of each group resulted from the same temperature were isolated in pairs and caged to eggs laying. The moths were provided with $10 \%$ honey bee solution for adult's feedind, and strips of muslin as a suitable site for oviposition feeding and. The cages were inspected daily until moth death to estimate the longevity of moths. The pre-oviposition and oviposition periods and the number of eggs as well as the hatchability percentages were estimated duration of different stages were recorded for each temperature. Data were subjected to the analysis of variance (ANOVA) and Duncan's multiple range test of means used (Duncan's, 1957).

The rates of development for $H$. armigera stages were determined by the simple formulation (1/tx100) 
for the five constant temperatures. The obtained data concerning the effectiveness of different constant temperature degrees on both immature and the adult stages of $H$. armigera were subjected to statistical analysis where the theoretical development threshold (to) and the accumulated thermal units (K) were determined according to the regression formula:

$$
\begin{gathered}
Y=a+b x \\
t_{0}=-a / b \& K=1 / b
\end{gathered}
$$

On the other hand, thermal units required for complete development of each stage was determined according to the equation of thermal summation (Blunk, 1923)

$$
\mathbf{K}=\mathbf{y}\left(\mathbf{T}-\mathbf{t}_{\mathbf{o}}\right)
$$

Where $\mathrm{y}=$ developmental duration of a given stage; $\mathrm{T}=$ temperature in degree centigrade; $t_{0}=$ lower threshold of development and $\mathrm{K}=$ thermal units in degree-days (DD's).

\section{RESULTS AND DISCUSSION}

Egg stage

\section{Incubation period}

Results represented in Table (1) indicated that the required time for completion of $H$. armigera embryogenesis decreased gradually as the temperature increased from 20 to $29^{\circ} \mathrm{C}$. The mean of incubation periods were $5.22,4.19,3.72$ and 2.41 days at, 20, 23, 26 and $329^{\circ} \mathrm{C}$; respectively. The lower threshold of embryonic development was determined and it was found to be $12.56^{\circ} \mathrm{C}$ as indicated in Fig.(1)..d The average thermal units expressed as degree-days required for completing the development of incubation period for eggs was 43.05 DD's as determined by the thermal summation equation $\mathrm{K}=\mathrm{y}(\mathrm{T}-12.56)$ according to Kajanshikov (1946). Generally, significant differences were found between the incubation periods of egg at ${ }^{\circ} \mathrm{C}$ and the other three temperatures, it indicated that embryonic development of the $H$. armigera was affected with the tested temperatures.

The four observed values for rate of eggs development at the four tested temperature degrees, gave also a remarkable good fit to the calculated temperature-velocity line having the formula $\mathrm{Y}=2.33 \mathrm{X}$ -29.3 ( Fig.1).

\section{Hatchability:}

Data represented in Table (1) stated that the highest hatchability percentage was $75.03 \%$ at $26^{\circ} \mathrm{C}$, whereas the lowest one was $44.48 \%$ at $20^{\circ} \mathrm{C}$. Statistically, there are significant differences between the hatchability percentages recorded at 20,23, 26 and $29^{\circ} \mathrm{C}$. It is clearly noticed that the constant temperature in the range of 23 to $29^{\circ} \mathrm{C}$ is the favorable zone for the hatching of $H$. armigera.

\begin{tabular}{|c|c|c|c|c|c|c|c|}
\hline \multirow[b]{2}{*}{$\begin{array}{l}\text { Temp } \\
\text { (degree) }\end{array}$} & \multicolumn{2}{|c|}{ Observed } & \multicolumn{2}{|c|}{ Expected } & \multirow[b]{2}{*}{$\mathbf{t}_{0}$} & \multirow[b]{2}{*}{$\begin{array}{c}\text { Degree of } \\
\text { days } \\
\text { (DDs) }\end{array}$} & \multirow[b]{2}{*}{$\begin{array}{c}\text { Hatchability } \\
\%\end{array}$} \\
\hline & $\begin{array}{c}\text { Incubation } \\
\text { Period } \\
\text { (days +/- S.E.) }\end{array}$ & $\begin{array}{c}\text { Rate of } \\
\text { development } \\
\%\end{array}$ & $\begin{array}{c}\text { Incubation } \\
\text { Period } \\
\text { (days +/- S.E.) }\end{array}$ & $\begin{array}{c}\text { Rate of } \\
\text { development } \\
\%\end{array}$ & & & \\
\hline$\overline{20}$ & $5.22^{\mathrm{a}}$ & 19.16 & 5.76 & 17.35 & & 38.84 & 44.48 \\
\hline 23 & $4.19^{b}$ & 23.87 & 4.11 & 24.35 & 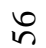 & 43.74 & 53.03 \\
\hline 26 & $3.72^{\mathrm{b}}$ & 26.88 & 3.19 & 31.35 & ป & 49.99 & 75.03 \\
\hline 29 & $2.41^{\mathrm{c}}$ & 41.49 & 2.61 & 38.35 & & 39.62 & 68.9 \\
\hline Average & 3.89 & 27.85 & 3.92 & 27.85 & & 43.05 & 60.36 \\
\hline
\end{tabular}

Table (1):Incubation period of $H$. armigera under different constant temperatures and its thermal requirements.

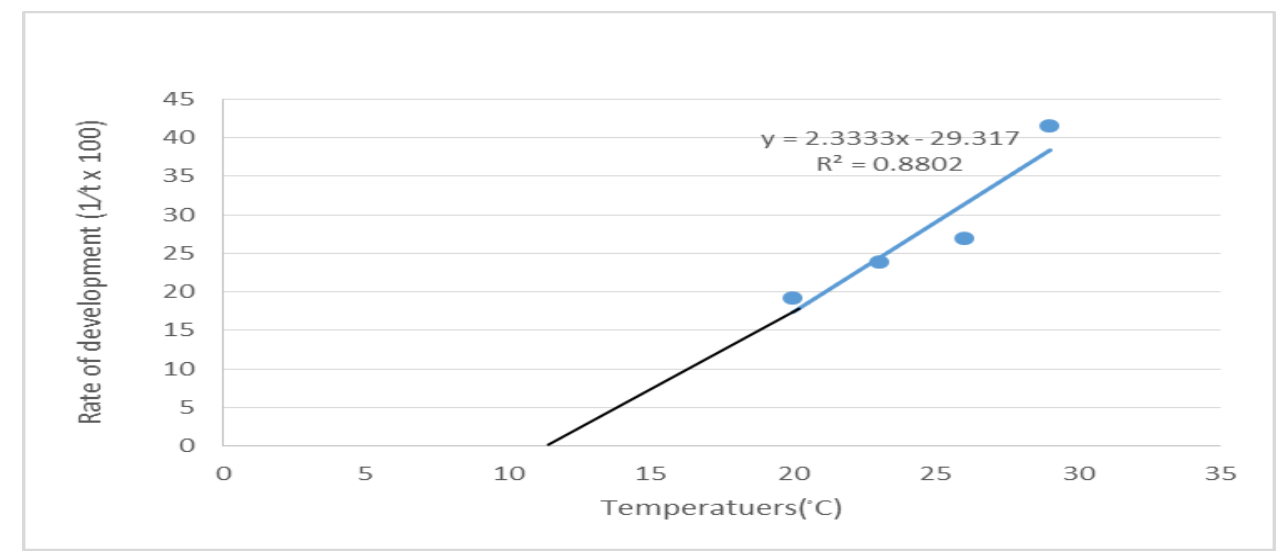

Fig. (1): Regression line of relationship between the rates of development of $\boldsymbol{H}$. armigera egg and different constant temperatures.

These results are accordance with the findings obtained by Kajanshikov (1946) who found that the linear relationship between temperature and rate of development can be expressed by the formula $\mathrm{K}=\mathrm{y}$ ( $\mathrm{T}$ - $\left.\mathrm{t}_{0}\right)$. The obtained results are supported by Gergis et al (1994), they revealed that the most favorable temperature for development of pink bollworm was $26^{\circ} \mathrm{C}$. In this field of study, Dahi (1997) stated that the 
lower of threshold of development for incubation period of pink bollworm eggs was $11.11^{\circ} \mathrm{C}$. The present results are going in line with those obtained by Yones et al. (2011). They recorded that the observed and expected of incubation period for $P$. gossypiella eggs decreased with increasing temperatures between 20 and $35^{\circ} \mathrm{C}$. They added that both observed as well as expected developmental percentages foe incubation period of eggs decrease as increasing temperatures, the lower threshold for incubation period was $991^{\circ} \mathrm{C}$ and the average thermal units required for incubation period was 72.11 degree-days. Kandil (2013), recorded that the threshold of incubation period $\left(\mathrm{t}_{\mathrm{o}}\right)$ of Earias insulana eggs was $12.8^{\circ} \mathrm{C}$ when the temperature ranged between 17 to $33^{\circ} \mathrm{C}$

\section{Larval duration}

As noticed in Table (2), it is obvious that the observed and expected larval duration values at five constant temperatures; 20, 23, 26 and $29^{\circ} \mathrm{C}$ were $28.28 \& 29.07,21.33 \& 21.74$ and $17.10 \& 17.36$ days; respectively. Statistically, there are obvious significant differences between the mean larval duration at the different four constant temperatures. Generally the developmental rates of the $H$. armigera larvae decrease with the increasing of the constant temperature from 20 to $29^{\circ} \mathrm{C}$. The lower threshold of development $\left(\mathrm{t}_{\mathrm{o}}\right)$ for larval stage was $11.09^{\circ} \mathrm{C}$.The mean values of thermal units required for larval development till pupation were 251.97, 254.04, 254.96 and 261.67 degree-days at $20,23,26$ and $29^{\circ} \mathrm{C}$; respectively. The average of total thermal units was 255.66 degree-days as determined by the thermal summation equation $\mathrm{K}=(\mathrm{T}-11.09)$.

The four observed values for the larval rate of development gave a remarkable fit to the calculated temperature - velocity line having the formula $\mathrm{Y}=0.387 \mathrm{X}-4.288$ (Fig.2).

These results are accordance with the findings obtained by Kajanshikov (1946) who found that the linear relationship between temperature and rate of development can be expressed by the formula $\mathrm{K}=\mathrm{y}$ ( $\mathrm{T}$ $\mathrm{t}_{0}$ ). Our results are in agreement with those published by Rania et al. (1977). They reported that the most favorable temperature for development and survival of the immature stage of a non-diapausing Indian strain of $P$. gossypiella, reared on artificial diet in the laboratory was $26^{\circ} \mathrm{C}$. At $32^{\circ} \mathrm{C}$, duration of the development stages was significantly shorter than at lower temperatures, but larval mortality was high. The results are going in line of the findings of Gergis et al. (1990). They reported that the development lower threshold for development of pink bollworm larvae was $10.26^{\circ} \mathrm{C}$ and they added that the effective thermal units required for completion of larval stage were 144.92 degree-days. The present investigation was accordance with those published by Yones et al. (2011). They stated that the observed as well as expected developmental rate of p. gossypiella larvae was decreased with increasing temperature from 20 to $35^{\circ} \mathrm{C}$. Also, they mentioned that the threshold $\left(\mathrm{t}_{\mathrm{o}}\right)$ of the larval developmental was $14.07^{\circ} \mathrm{C}$ and the average of summation thermal units required to the development of the larval stage was 166.38 degreedays. Working on the spiny bollworm, Earias insulana, Kandil, (2013) revealed that the lower threshold of larval development $\left(\mathrm{t}_{\mathrm{o}}\right)$ was $14.41^{\circ} \mathrm{C}$, and the thermal unit required for larval development was 131.33 degreedays.

Table (2): larval duration of $H$. armigera under different constant temperatures and its thermal requirements.

\begin{tabular}{|c|c|c|c|c|c|c|c|}
\hline \multirow[b]{2}{*}{$\begin{array}{l}\text { Temp } \\
\text { (degree) }\end{array}$} & \multicolumn{2}{|c|}{ Observed } & \multicolumn{2}{|c|}{ Expected } & \multirow[b]{2}{*}{$\mathbf{t}_{\mathbf{0}}$} & \multirow[b]{2}{*}{$\begin{array}{l}\text { Degree of } \\
\text { days (DDs) }\end{array}$} & \multirow[b]{2}{*}{$\underset{\%}{\text { Pupation }}$} \\
\hline & $\begin{array}{c}\text { Larval } \\
\text { duration (days }+/- \text { S.E.) }\end{array}$ & $\begin{array}{c}\text { Rate of } \\
\text { development } \%\end{array}$ & $\begin{array}{c}\text { Larval duration } \\
\text { (days +/- S.E.) }\end{array}$ & $\begin{array}{c}\text { Rate of } \\
\text { development } \%\end{array}$ & & & \\
\hline 20 & $28.28^{\mathrm{a}}$ & 3.36 & 29.07 & 3.44 & & 251.97 & 73.33 \\
\hline 23 & $21.33^{b}$ & 4.69 & 21.74 & 4.6 & 8 & 254.04 & 74.12 \\
\hline 26 & $17.1^{\mathrm{c}}$ & 5.85 & 17.36 & 5.76 & 二 & 254.96 & 92.04 \\
\hline 29 & $14.61^{\mathrm{d}}$ & 6.84 & 14.45 & 6.92 & & 261.67 & 72 \\
\hline Average & 20.33 & 5.19 & 20.66 & 5.18 & & 255.66 & 77.87 \\
\hline L.S.D & & & & & & & \\
\hline
\end{tabular}

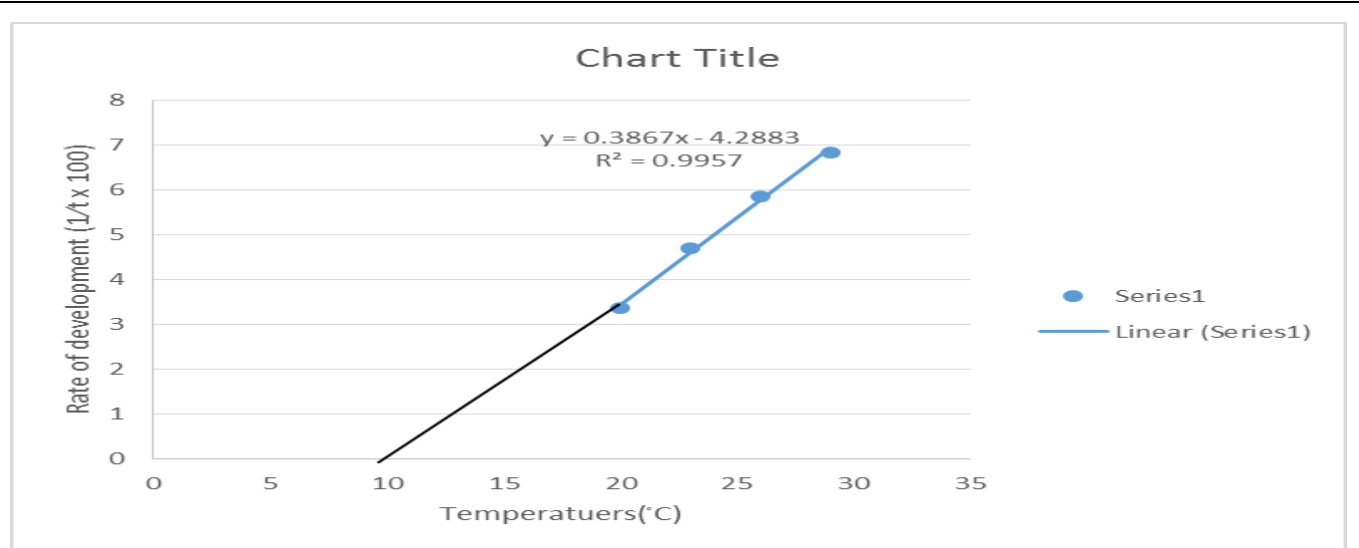

Fig.(2): Regression line of relationship between the rates of development of $\boldsymbol{H}$. armigera larvae and different constant temperatures. 


\section{Pupation rate:}

Data given in Table (2) indicated that the highest pupation rate of spiny bollworm larvae, was $92.04 \%$ at $26^{\circ} \mathrm{C}$ followed by $90.27 \%$ at $30^{\circ} \mathrm{C}$, whereas an extremely reduction of this rate of pupation was occurred 20, 23 and $29^{\circ} \mathrm{C}$. Also, it is clear that the constant temperatures in the range of $26^{\circ} \mathrm{C}$ was the effective temperature zone for $H$. armigera pupation and the optimum degree of temperature may be around $26^{\circ} \mathrm{C}$, where the highly pupation percentage was recorded. Statistically, there are significant differences between the value of pupation rates at the four different constant temperatures; i.e. $20,23,26$ and $29^{\circ} \mathrm{C}$.

The obtained results are supported by Dahi (2003) and Kandil (2013). They concluded that the highest pupation rate of $E$. insulana was observed when the larvae reared on $25^{\circ} \mathrm{C}$.

\section{Pupal stage:}

\section{Pupal duration:}

Concerning the effect of the constant temperatures; i.e.20, 23, 26 and $29{ }^{\circ} \mathrm{C}$ on the pupal duration of $H$. armigera, data represented in Table (3), revealed that the pupal period decrease as temperature increased. The average observed and expected durations were $26.03 \& 26.39, \quad 20.06 \& 19.96, \quad 15.53 \& 15.56$ and $13.02 \& 13.02$ days at $20,23,26$ and $29^{\circ} \mathrm{C}$; respectively. The analysis of variance showed significant differences between the mean of pupal duration at all temperatures. The lower threshold of development $\left(\mathrm{t}_{\mathrm{o}}\right)$ for the American bollworm pupae was $11.23^{\circ} \mathrm{C}$. The thermal units required for pupal duration completion till adult emergence were 228.28, 236.11, 229.38 and 231.37 DD's at20, 23, 26 and $29^{\circ} \mathrm{C}$; respectively. The average of total thermal units was231.29 degree-days as determined by the thermal summation equation $\mathrm{K}=\mathrm{y}(\mathrm{T}-11.23)$.
The four observed values for the pupal rate of development gave a remarkable fit to the calculated temperature - velocity line having the formula $\mathrm{Y}=$ 0.432 X -4.855 (Fig.3).

Our results are accordance with those findings by Rashwan (2009), she stated that the lower threshold for the developmental pupa stage of $P$. gossypiella was $11.7^{\circ} \mathrm{C}$ and the average of the total thermal units required for completion of pupal stage till the adult emergence was 198.52 degree-days. The obtained results that mentioned previously are in agreement with those published by Yones et al. (2011). They recorded that the observed as well as expected pupal duration of the pink bollworm decreased as temperature increased, their data recorded that the lower threshold pupal development was $9.57^{\circ} \mathrm{C}$, and the average of the total thermal units required for completion of pupal stage till the adult emergence was 248.70 degree-days. Many other investigators studied also the effects of constant temperatures on the biological aspects of different insects including their immature stages, among of them, Kandil (2013) on Earias insulana.

\section{Adult emergence rate:}

Data summarized in Table (3) indicated that the highest adult emergence percentage was occurred at $26^{\circ} \mathrm{C}$, which being $85.87 \%$; whereas the lowest one was $66.48 \%$ at $20^{\circ} \mathrm{C}$. On the other hand, the adult emergence rates at the other two temperatures; i.e. 23 $29^{\circ} \mathrm{C}$ were 78.52 and $72.73 \%$; respectively. Statistical analysis of variance referred to significant differences between the adult emergence figures recorded at constant temperatures $20^{\circ} \mathrm{C}$, and the other three constant temperatures 23,26 and $29^{\circ} \mathrm{C}$; whereas there are no significant differences between the adult emergence at 23,26 and $29^{\circ} \mathrm{C}$.

Table (3): Pupal duration of $H$. armigera under different constant temperatures and its thermal requirements.

\begin{tabular}{|c|c|c|c|c|c|c|c|}
\hline \multirow[b]{2}{*}{$\begin{array}{l}\text { Temp } \\
\text { (degree) }\end{array}$} & \multicolumn{2}{|c|}{ Observed } & \multicolumn{2}{|c|}{ Expected } & \multirow[b]{2}{*}{$\mathbf{t}_{0}$} & \multirow[b]{2}{*}{$\begin{array}{c}\text { Degree of } \\
\text { days (DDs) }\end{array}$} & \multirow[b]{2}{*}{$\begin{array}{c}\text { Adult } \\
\text { emergence \% }\end{array}$} \\
\hline & $\begin{array}{c}\text { Pupal duration } \\
\text { (days +/- S.E.) }\end{array}$ & $\begin{array}{c}\text { Rate of } \\
\text { development \% }\end{array}$ & $\begin{array}{l}\text { Pupal duration } \\
\text { (days +/- S.E.) }\end{array}$ & $\begin{array}{c}\text { Rate of } \\
\text { development \% }\end{array}$ & & & \\
\hline 20 & $26.03^{\mathrm{a}}$ & 3.84 & 26.39 & 3.79 & & 228.28 & 66.48 \\
\hline 23 & $20.06^{\mathrm{b}}$ & 4.99 & 19.96 & 5.01 & 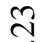 & 236.11 & 78.52 \\
\hline 26 & $15.53^{\mathrm{c}}$ & 6.44 & 15.67 & 6.38 & 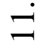 & 229.38 & 85.87 \\
\hline 29 & $13.03^{\mathrm{d}}$ & 7.68 & 13.02 & 7.68 & & 231.37 & 72.73 \\
\hline Average & 18.66 & 5.74 & 18.76 & 5.72 & & 231.29 & 75.90 \\
\hline L.S.D & & & & & & & \\
\hline
\end{tabular}

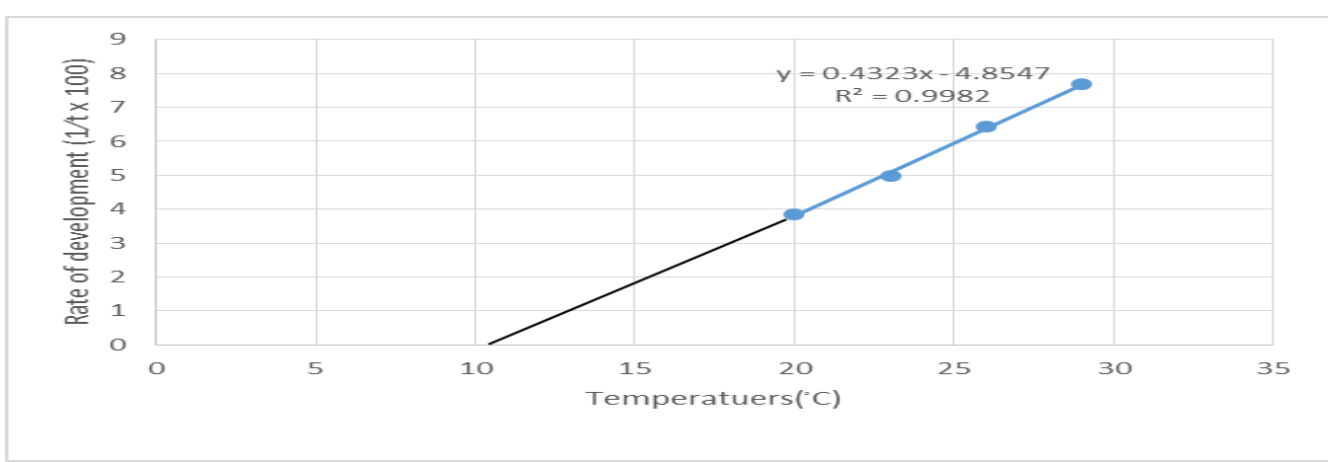

Fig.(3): Regression line of relationship between the rates of development of $\boldsymbol{H}$. armigera pupae and different constant temperatures. 
These results combined with other parameter such as the values of thermal units required for pupal development at temperature range from 20 to $29^{\circ} \mathrm{C}$ indicating that this range of temperature could be considered at the optimum zone of effective temperature for pupal development and the adult emergence. The results are accordance with those published by Dahi (2010) on the H. armigera. Who indicated that the value of thermal units required for pupal development at temperature range from 22 to $32^{\circ} \mathrm{C}$ indicating that this range of temperature could be considered as the optimum zone of effective temperature for pupal development .Our results are going in line with those obtained by Kandil (2013). She published that the highest adult emergence rate for the spiny bollworm, $E$. insulana was occurred at $26^{\circ} \mathrm{C}$ which being $91.1 \%$.

\section{Adult stage:}

Pre-oviposition period:

Data illustrated in Table (4) showed that there was an inverse relationship between the pre-oviposition period and temperatures. It is clear that the mean time required for maturation of the ovary and starting to egg lying, decreased as the temperature increased from 5.25 days at $20^{\circ} \mathrm{C}$ to 2.51 days at $29^{\circ} \mathrm{C}$. Statistical analysis of the obtained results revealed that there are significant differences between the average of pre-oviposition period at $20^{\circ} \mathrm{C}$ and all other regimes. On the other hand, there are no significant differences between the values at $20 \& 25$ and between $25 \& 30$. Regarding the developmental thresholds, results shown in Table (4) indicated that the lower threshold of development was $9.99^{\circ} \mathrm{C}$. It is obvious that the raising of temperature accelerated the rate of development of the female ovary and reached faster to maturation. Concerning the thermal units required for the development of ovary at tested temperature, the required thermal units were 52.55, 40.98, 47.71 and 47.72 degree-days at 20, 23,26 and $29^{\circ} \mathrm{C}$; respectively. The average of thermal units was 47.24 degree-days as determined by thermal summation equation $\mathrm{K}=\mathrm{y}$ ( $\mathrm{T}-9.99)$.
The four observed values for these periods gave a remarkable fit to the calculated temperature - velocity line having the formula $\mathrm{Y}=2.139 \mathrm{X}-21.364$ (Fig.4).

It could be concluded that the optimum zone of temperature for ovary development and maturity was between 23 and $29^{\circ} \mathrm{C}$ for $H$. armigera, this conclusion is supported by the findings of Rania et al. (1977) and Rashwan (2009) on the pink bollworm, Dahi (2003) on spiny bollworm, Dahi (2010) on H. armigera, Kandil (2013) on spiny bollworm and Abdel-Salam (2013) on pink bollworm.

\section{The generation:}

The mean duration of generation at different constant temperature regimes could be calculated using two different calculation methods, at the first method the mean duration of generation was considered as the mean times between egg-deposition and, the beginning of egg deposition by emerged females $\left(F_{1}\right)$; i.e. from egg deposition to the end of pre-oviposition period). The second method, the mean generation times were determined as the total of mean durations of different developmental stages, i. e. incubation period, larval stage, pupal stage and pre-oviposition period. Theoretically, the results obtained from these methods show approximate value for mean durations of generation at different constant temperature regimes.

According to the second mod which has been applied in the present study, the results given in Table (5) ,illustrated that the mean duration of the observed and expected generation for $H$. armigera were $64.78 \& 64.94,48.73 \& 48.78,39.33 \& 39.22$ and 32.55 and 32.68 days at $20,23,26$ and $29^{\circ} \mathrm{C}$; respectively. The data refer to the acceleration of rate development generation with the increasing of temperature, where it reached the maximum velocity at $29^{\circ} \mathrm{C}$. Statistical analysis showed significant differences among the values of generation duration at the tested constant temperatures.

Table (4): Pre - ovposition of $H$. armigera under different constant temperatures and its thermal requirements.

\begin{tabular}{|c|c|c|c|c|c|c|}
\hline \multirow[b]{2}{*}{$\begin{array}{l}\text { Temp } \\
\text { (degree) }\end{array}$} & \multicolumn{2}{|c|}{ Observed } & \multicolumn{2}{|c|}{ Expected } & \multirow[b]{2}{*}{$\mathbf{t}_{\mathbf{0}}$} & \multirow[b]{2}{*}{$\begin{array}{l}\text { Degree of } \\
\text { days (DDs) }\end{array}$} \\
\hline & $\begin{array}{c}\text { Pre - ovposition period } \\
\text { (days +/- S.E.) }\end{array}$ & $\begin{array}{c}\text { Rate of } \\
\text { development \% }\end{array}$ & $\begin{array}{c}\text { Pre - ovposition } \\
\text { period(days +/- S.E.) }\end{array}$ & $\begin{array}{c}\text { Rate of } \\
\text { development \% }\end{array}$ & & \\
\hline$\overline{20}$ & $5.25^{\mathrm{a}}$ & 19.05 & 4.67 & 21.42 & & 52.55 \\
\hline 23 & $3.15^{\mathrm{b}}$ & 31.75 & 3.59 & 27.84 & 2 & 40.98 \\
\hline 26 & $2.98^{\mathrm{b}}$ & 33.56 & 2.92 & 34.26 & $\hat{a}$ & 47.71 \\
\hline 29 & $2.51^{\mathrm{b}}$ & 39.84 & 2.46 & 40.68 & & 47.72 \\
\hline Average & 3.47 & 31.05 & 3.41 & 31.05 & & 47.24 \\
\hline L.S.D & & & & & & \\
\hline
\end{tabular}




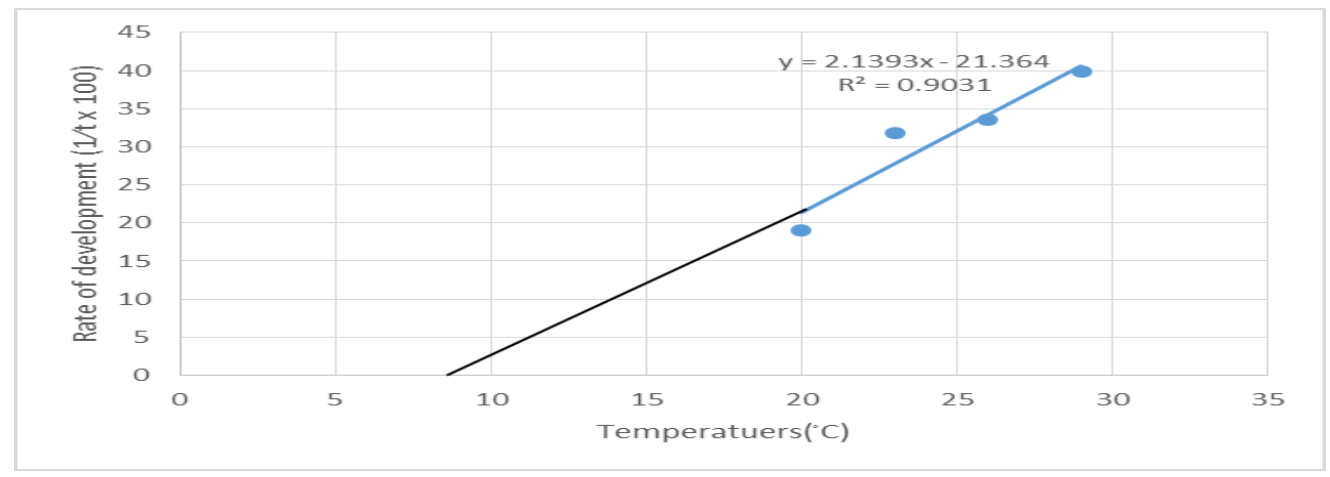

Fig.(4): Regression line of relationship between the rates of development of $\boldsymbol{H}$. armigera pre-oviposition period and different constant temperatures.

Table (5): Duration of $\boldsymbol{H}$. armigera generation under different constant temperatures and its thermal requirements.

\begin{tabular}{|c|c|c|c|c|c|c|}
\hline $\begin{array}{l}\text { Temp } \\
\text { (degree) }\end{array}$ & $\begin{array}{l}\text { Observe } \\
\begin{array}{c}\text { Duration of generation } \\
\text { (days }+/ \text { - S.E. })\end{array}\end{array}$ & $\begin{array}{c}\text { d } \\
\text { Rate of } \\
\text { development \% }\end{array}$ & $\begin{array}{c}\text { Expect } \\
\begin{array}{c}\text { Duration of generation } \\
\text { (days }+/ \text { - S.E. })\end{array}\end{array}$ & $\begin{array}{c}\text { Rate of } \\
\text { development } \%\end{array}$ & $\mathbf{t}_{0}$ & $\begin{array}{c}\text { Degree of } \\
\text { days (DDs) }\end{array}$ \\
\hline$\overline{20}$ & $64.78^{\mathrm{a}}$ & 1.54 & 64.94 & 1.54 & & 588.2 \\
\hline 23 & $48.73^{\mathrm{b}}$ & 2.05 & 48.78 & 2.05 & న̆ & 588.66 \\
\hline 26 & $39.33^{c}$ & 2.54 & 39.22 & 2.55 & 0 & 593.1 \\
\hline 29 & $32.55^{\mathrm{d}}$ & 3.07 & 32.68 & 3.06 & & 588.5 \\
\hline Average & 46.35 & 2.30 & 46.41 & 2.30 & & 589.62 \\
\hline L.S.D & 1.999 & & & & & \\
\hline
\end{tabular}

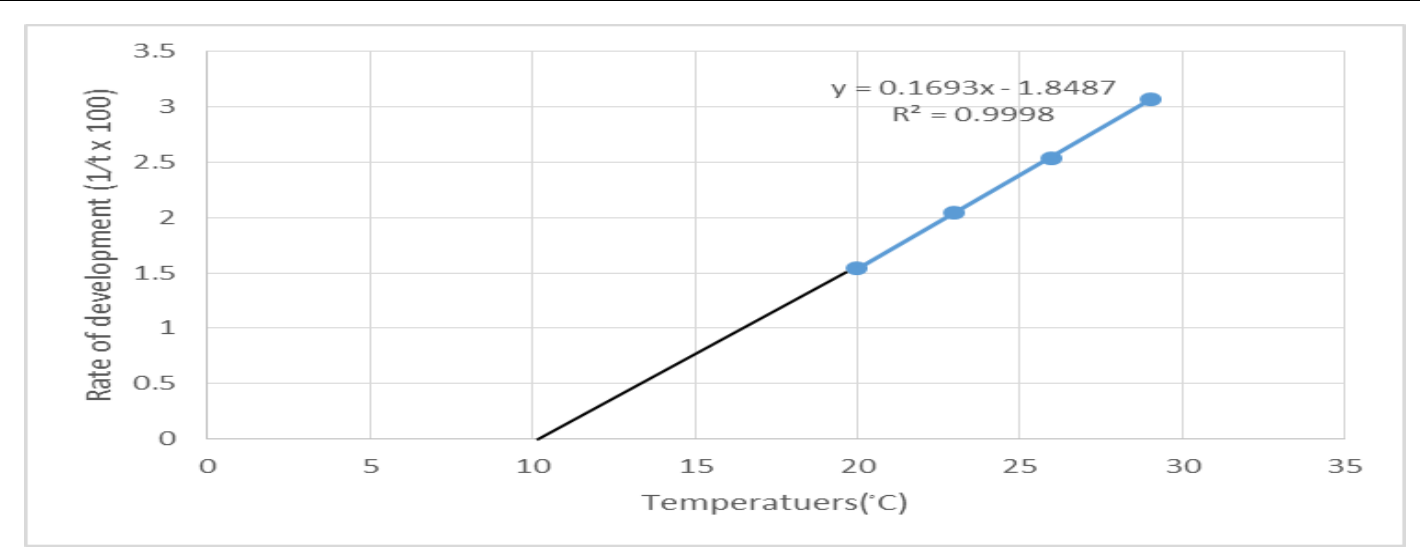

Fig.(5): Regression line of relationship between the rates of development of $\mathrm{H}$. armigera generation and different constant temperatures.

The lower threshold of the generation development $\left.\left(\mathrm{t}_{\mathrm{o}}\right)\right) \quad$ was $10.92^{\circ} \mathrm{C}$. The complete development of the generation required 588.20, 588.66, 593.10 and 588.50 degree-days at $20,23,26$ and $29^{\circ} \mathrm{C}$; respectively. Statistical analysis showed no significant differences between values of accumulated thermal units required for completion generation at among constant temperatures used under this study. Thermal summation method, represents the hyperbolic relationship between temperature and developmental time given by the equation: $\mathrm{Y}=(\mathrm{T}-10.92)=589.62$ DD's, derived from the linear regression equation: $\mathrm{Y}=$ $0.169 \times-1.849(\mathrm{r}=0.99)$. The lower threshold of development $\left(\mathrm{t}_{\mathrm{o}}\right)$ could be estimated graphically by extrapolation from Fig. (5).

Data summarized in Table (6), showed the female and male longevity of $H$. armigera under the different constant temperatures. The longevity was $19.48,16.83,13.50$ and 10.97 days for female; 18.11, $13.56,11.05$ and 8.01 days for male at 20,23, 26 and $29^{\circ} \mathrm{C}$; respectively.

Discussion of the foregoing results, concerning the adult stage aspects and generation of the pink bollworm, $H$. armigera, it could be seen from the results recorded herein a harmony with those obtained by various investigators. The results are in agreement with those reported by Dahi (2003), who revealed that the lower threshold for completion the generation of $\mathrm{E}$. insulala was $9.9^{\circ} \mathrm{C}$, and the average of thermal units required for completion the generation was 499.57 DD's. he results are going in line with those published by Dahi (2010), he stated that the lower threshold for completion the generation of $\mathrm{H}$. armigera was $10.87^{\circ} \mathrm{C}$, and the average of thermal units required for completion 
the generation was 557.5 DD's In this field of study, Kandil (2013) reported that the lower threshold for completion generation of $\mathrm{E}$, insulana was $12.85^{\circ} \mathrm{C}$ and the average of thermal units required for completion the generation was 346.19 DD's. Also, the results of the present study are accordance with Yones et al. (2011). They stated that the lower threshold of development for completion generation of pink bollworm was $12.03^{\circ} \mathrm{C}$ and the average thermal units required for completion of generation was 499.71 degree-days.

Data summarized in Table (6), showed the female and male longevity of $H$. armigera under the different constant temperatures. The longevity was $19.48,16.83,13.50$ and 10.97 days for female; 18.11, 13.56, 11.05 and 8.01 days for male at 20, 23, 26 and $29^{\circ} \mathrm{C}$; respectively.

Table (6): Adult longevity of $\boldsymbol{H}$. armigera under different constant temperatures.

\begin{tabular}{lccccc}
\hline $\begin{array}{l}\text { Temp } \\
\text { (degree) }\end{array}$ & Pre - ovposition & $\begin{array}{c}\text { Female Longevity (days) } \\
\text { Ovposition }\end{array}$ & Post - ovposition & Total & $\begin{array}{c}\text { Male Longevity } \\
\text { (days) }\end{array}$ \\
\hline 20 & 5.25 & 12.75 & 1.48 & $19.48^{\mathrm{a}}$ & $18.11^{\mathrm{a}}$ \\
23 & 3.15 & 12.93 & 0.75 & $16.83^{\mathrm{b}}$ & $13.56^{\mathrm{b}}$ \\
26 & 2.98 & 9.51 & 1.01 & $13.5^{\mathrm{c}}$ & $11.05^{\mathrm{c}}$ \\
29 & 2.51 & 7.33 & 1.13 & $10.97^{\mathrm{d}}$ & $8.01^{\mathrm{d}}$ \\
Average & 3.47 & 10.63 & 1.09 & 15.20 & 12.68 \\
L.S.D & & & & 1.7629 & 1.8989 \\
\hline
\end{tabular}

\section{Fecundity and fertility:}

Results obtained in Table (7) indicated that the adult female of $E$. insulana deposited eggs under all tested temperatures. The average total number of eggs deposited by female throughout its life span were 214.52, 517.54, 668.33 and 291.50 eggs at 20,23, 26 and $29^{\circ} \mathrm{C}$; respectively. The data clearly indicated that the constant temperatures regime of 23 and $26^{\circ} \mathrm{C}$ were considered the optimum degree for eggs lying. Statistical analysis showed significant differences in the fecundity at the different tested temperatures of 20, 23, 26 and $29^{\circ} \mathrm{C}$. Reviewing these results, it could be concluded that temperature is considered as an important limiting factor for the adults, since it affects the fecundity of females and longevity of both sexes. The present results are accordance with Dahi (2010). He stated that the constant temperatures of 22 and $27^{\circ} \mathrm{C}$ were considered as the optimum degree of eggs laid by female of $H$. armigera, which were 857.4 and 645.5 eggs/ female; respectively. The obtained results are going in line with those published by Kandil (2013), She recorded that the constant temperature of $26^{\circ} \mathrm{C}$ was considered as optimum degree of eggs laid by female of E. insulana, which being 273.66 eggs/female. In this field of study. Also, Hennerberry and Leal (1979) stated that the reduction in oviposition rate and egg viability at high temperature may due to either killed function sperm or interferes with sperm transfer or both.

Generally, the deleterious effect of the high temperature on the adult fecundity are considered as one of the principle factors for the relatively low infestation level during summer season, when temperature is extremely high.

Regarding the egg fertility (as indicted by egg hatchability) laid by the female, which emerged under the constant temperature regimes and incubated also at the same conditions, it is obvious that temperature considered a vital factor for egg (Table 7). The lowest fertility percentages were occurred at 20 and $29^{\circ} \mathrm{C}$, where only 44.48 and $53.45 \%$ of deposited eggs / female hatched. The highest fertility percentage of eggs was recorded at $26^{\circ} \mathrm{C}(85.13 \%)$ which considered the optimum temperature for hatchability. Statistical analysis of the results showed significant differences among the fertility rates at all tested degrees of temperature. According to several authors, these results are in agreement with those published by Dahi, 2003 Kandil, 2013 on E. insulana and Abdel-Salam, 2013 on Pectinophora gossypiella.

Table (7): Effect of different constant temperatures on fecundity and fertility of $\mathrm{H}$. armigera.

\begin{tabular}{lcc}
\hline Temp (degree) & Fecundity (eggs/female) & Hatchability $\%$ \\
\hline 20 & 214.52 & 44.48 \\
23 & 517.54 & 72.9 \\
26 & 668.33 & 85.13 \\
29 & 291.5 & 53.48 \\
Average & 422.97 & 64.00 \\
\hline
\end{tabular}

\section{REFFERENCES}

Abdel-Salam, Dalia A.; S. A. El-Rafai; A. A. Khidr and G. B. El-Saadany (2013): Use of rapd technique to study genetic variation of field colony collected pink bollworm, Pectinophora gossypiella (Saund.).Egypt. J. of Appl. Sci.,28 (5):76-93.
Blunk, M. (1923): Die Entwicklung Von Dytiscus marginalis L. Vom. E. bis Zur Imago,2 Teil. Die Metamorphase Zracht-Wiss. Sool.,121-171.

Dahi, H. F. (1997): New approach for management the population of cotton leaf worm, Spodoptera littoralis (Boisd.) in Egypt. M. Sc. Thesis, Fac. Of Gric. Caito Univ., 149 pp. 
Dahi, H. F. (2003): Predicting the annual generations of the spiny bollworm, Earias insulana (Boisd.) (Lepidoptera: Actiidae). PhD. Thesis, Faculty of Agriculture Cairo university, $184 \mathrm{pp}$.

Dahi, H. F. (2010): Lower threshold of development and accumulated heat units requirements for different stages of the American bollworm, Helicoverpa armigera (Hub.). Bull. Ent. Soc. Egypt, 87, 225-238.

Duncan, D. B. (1955): Multiple range and multipletests.Biometrics, 11: 1-42.

Gegis, M. F.; M. A. Rizk; M. A. Makadey and A. Hussein (1994): Relationship between temperature and rate of development of cotton leaf worm, Spodoptera littoralis (Bisd.). Minia J. Agric. Res.\& Dev., 14: 235-243.

Gergis, M. F.; El- A. Moftah; M. A. Soliman and A. A. Khidr (1990): Temperature Dependent development and functional responses of pink bollworm, Pectinophora gossypiella. Assiut J. Agric. Sci., 21: 119-127.

Henneberry,T. J. and M. P. Leal (1979): Pink bollworm: Effect of temperature, photoperiod and light intensity, moth age and mating frequency on oviposition and viability. J. Econ. Entomol., 72: 489-492.

Ives, W. G. H. (1973): heat units and outbreaks of Malacosoma disstria.( Can Entomol. 105, 529, 543).
Kajanshikov, N. B. (1946): Kb0npocy oznbhehhom tempnueckom ontnmyme 8-olabnlbhoctn npuoueccob pazbntna hacekomblx bothowehnn tempnuecknx bilnahnn. (300-Lx4 Prl. 25, C. 27-35).

Kandil, Mervat A. A. (2013): Relationship between temperature and some biological aspects of Earias insulana (Boisd.) Egypt. Acad. J. Biolog. Sci., 6 (1): 11-20.

Matthews, G. A. and J. P. Turnstile (2001): Insect pests of cotton. (UK,Univ. Press, Cambridge, 593pp).

Rania, A. K.; R. A. Bell and R. B. Carlson (1977): Influence of temperature on development of an Indian strain of the pink bollworm in the laboratory and observations on fecundity. Ann. Ent..,Soc. Amer., 70 (4): 628-630.

Rashwan, S. R. (2009): Predicting the changes in the population density of some cotton insect pests. Ph. D. Thesis, Fac. Of Agric., Ain Shams Univ. $164 \mathrm{pp}$.

Wagner, T. L.; H. I. WU; P. J. H. sharpe; R. M. Schoolfield and R. N. Coulson (1984): Modeling insect development rates: A Literature review and application of a biophysical model. (Ann. Entomol., Soc. Amer., 77 : 208-225).

Yones, M. S.; H.A. Abd Elrahman; A. E. Abo Hadid; S. M. Arafat and H. F. Dahi (2011): heat unit requirements for development of the pink bollworm, Pectinophora gossypiella (Saund.), Acad. J. Biolog.Sci., 4 (1): 115-122.

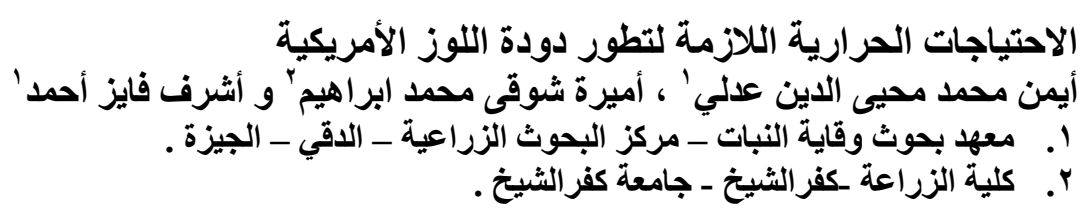

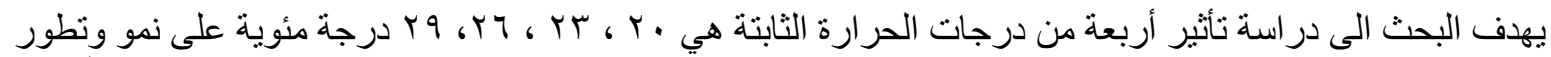

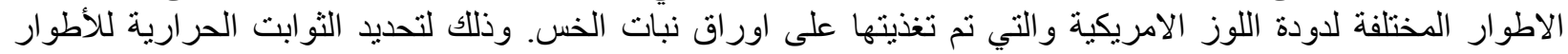

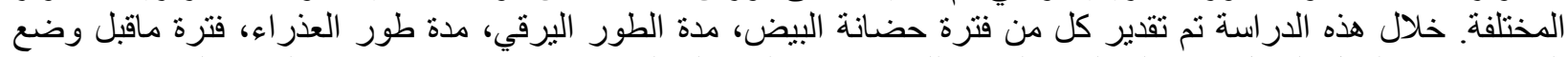

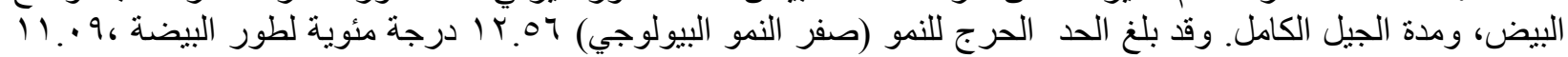

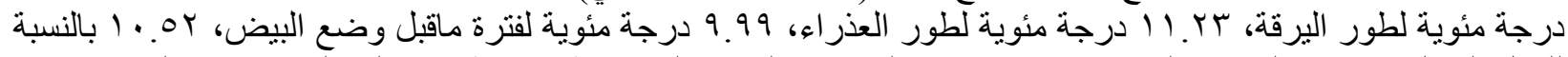

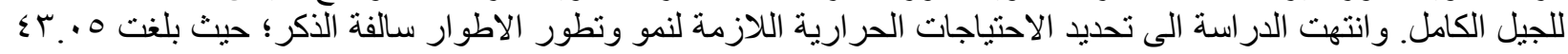

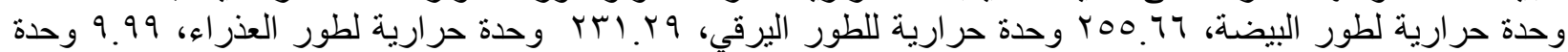

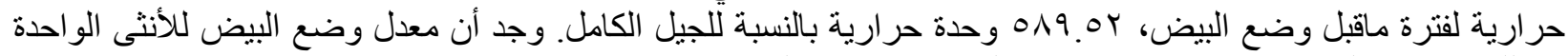

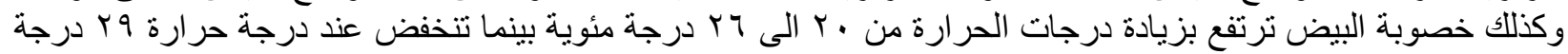
منؤية. 